\title{
The Flipped Classroom Used in Teaching of Environmental Chemistry at the University for Nationalities
}

\author{
Yue Peng \\ College of Chemistry and Environmental Protect Engineering, Southwest Minzu University, \\ Chengdu, China, 610041
}

Pengyue2000@163.com

Keywords: Flipped classroom, Teaching of environmental chemistry, Undergraduate education

\begin{abstract}
Flipped Classroom supported by information technology is a new kind of teaching model, but there are some problems in the practice of flipped classroom. In this paper the design of flipped classroom centered by learners was presented. This kind of flipped classroom was applied in the teaching of Environmental chemistry in the University for Nationalities. The teaching effects show that the new teaching model can improve the teaching quality and innovation ability of students remarkably. The following conclusions can be drawn from this study: learners are the dominants in the flipped classroom. Teacher, content of courses and adaptability of the learners should be taken into account for the design of flipped classroom. The purpose of design is to guide the learners' study demand, construct reasonable learning values, and mobilize learning enthusiasm. The teacher of the flipped classroom should pay attention to the individual difference to cultivate innovative talents.
\end{abstract}

\section{Introduction}

In the time of innovation and development, with the information technology changing rapidly, the active college students need different learning forms to satisfy their individualized learning needs. Undergraduate teaching faces the requirements for innovation and integration. The characteristic differences of learners are ignored in the traditional classroom. It is difficult to satisfy the requirement of the undergraduate teaching in the modern era by the face to face teaching form. With the support of information technology, a novel teaching form, Flipped classroom, came into being. It uses the information technology to transfer knowledge out of class and internalize knowledge in class ${ }^{[1][2]}$,

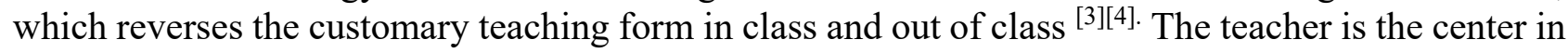
the traditional classroom, mainly in teaching the content of the course. Students are the center in the flipped classroom ${ }^{[5]}$, mainly in the exploration of knowledge. The two teaching forms are distinct in classroom subjects, and the time sequence of knowledge transfer and internalization is also unlike. Changing the traditional classroom teaching form and introducing flipped classroom is the innovation of teaching form and the integration of teaching and information technology. At present, the teaching form of flipped classroom is utilized more in primary and secondary schools teaching than undergraduate teaching, because of various subjects and professional teaching content in university.

In this study, the flipped classroom was used and researched at the University of Nationalities in order to explore the model of flipped classroom which takes the learners as the dominants and conforms to the practice of national higher education. The flipped classroom led by students was used in the teaching of environmental chemistry and the teaching effect was analyzed.

\section{Materials and methods}

\subsection{Normal flipped classroom}

In the use of flipped classroom, instructional design is the primary. The instructional design is distinctive for flipped classroom. The traditional class teaching is mainly designed for class teaching, while the flipped classroom design includes not only for teaching in class, but also for studying out of class ${ }^{[6]}$, which is indicated by the figure 1 . The design for students studying out of class involves 
more content than the design for teaching in class. Students of flipped classroom need detailed PPT for the self-study of the course. They can master the course knowledge through self-study.

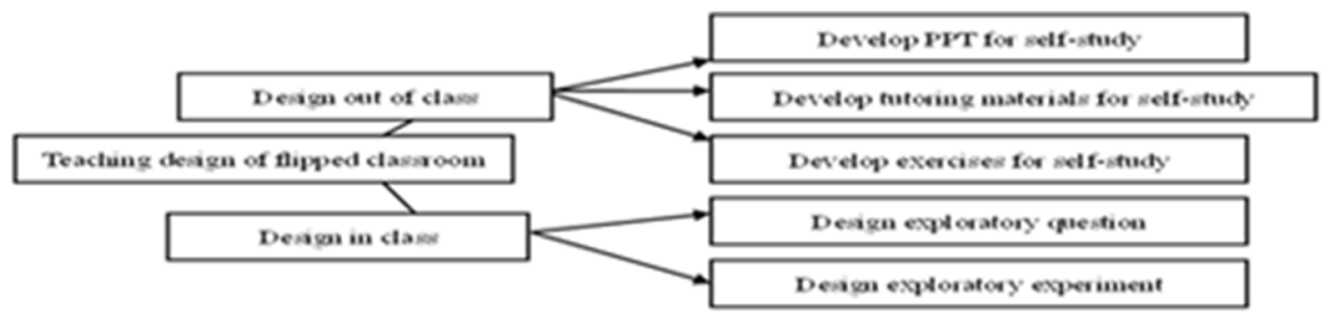

Fig. 1 The design of normal Flipped Classroom

\subsection{Problems to be resolved in use of flipped classroom}

The flipped classroom supported by information technology can satisfy personalized learning need. Students of the University for Nationalities come from different regions. There are substantial differences in learning basic between students. So when the overall model was implemented in the teaching of university for nationalities, the problems arise.

\subsubsection{Adaptability of content}

Flipped classroom requires students to learn knowledge through self-study. Being dependent on the study, the effective time of self-study is usually about 20 minutes. So teachers need to fragment teaching contents when preparing PPT for students' self-learning. The content of every teaching fragment should be not so long.

In self-study out of class, it is difficult for students to accept abstract, difficult basic theories and complex application knowledge. Fragmentation of teaching content makes it difficult for students to the teaching content that links multiple knowledge points. However, when the flipped classroom is applied to thematic or case based teaching of applied basic theory, the teaching effectiveness is good. For example, in the teaching of environmental chemistry, when we adopted the flipped classroom teaching method for the elementary theory of photochemical reaction, some students failed to understand and master the basic process of photochemical reaction out of class. After students mastered the rudimentary knowledge of photochemical reaction, the flipped classroom was applied to the teaching of photochemical smog, and the teaching consequences became good. So the flipped classroom is not suitable for all contents. Teachers should choose the applicable teaching content according to the actual situation. Generally it is not apt to adopt flipped classroom in elementary theoretical knowledge. Apply knowledge is appropriate to the flipped classroom.

\subsubsection{Learners' initiative}

The subject of the flipped classroom is the learners, the students. Out of class and in class, we are required to mobilize the initiative of students. Some learners may not be satisfied with flipped classroom ${ }^{[7]}$. The interesting questions utilized out of class should be designed, in order to let learners find their interest and finish the study out of class by exploring the problems. The learning interest and learning ability are different students. If designed problems were too complicated, students with poor learning background should give up the study out of class with their own frustrations. If designed problems were too simple, students with good learning foundation should lose interest owing to the lack of challenge in studying. So some questions should be designed, and the degree of difficulty of the questions is modified in order to help learners find their study interesting and stimulate the spirit of exploration.

In class learners display, test and exchange their achievement of self-study. They can gain a sense of achievement in learning, and study each other. If learners were not able to express positively, the presentation and discussion in class can't be carried out, and the tasks in class can't be completed. So teacher's operational guidance is needed in class. Teachers should inspire the enthusiasm of the learners to display and explore. 


\subsubsection{Monitoring of learning quality}

Monitoring of learning quality plays an important role in achieving the goal of flipped classroom. The learning of content in flipped classroom is accomplished by learners out of class, which is different from studying in class. There is no class teacher to control the learning process, and learning is done by learner autonomy. So teachers need to monitor the effect of completion in time, correct and make up for the lack of learning out of class, in order to ensure the timely completion of teaching tasks and the realization of teaching objectives.

\subsection{Flipped classroom led by learners}

The purpose of undergraduate teaching is to enable students to master the ways to understand and transform the objective world, and cultivate their scientific literacy and creativity by imparting knowledge. Constructivism maintains that everyone has his own understanding of the empirical world ${ }^{[8]}$. This understanding is related to everyone's experience, psychology and belief. Knowledge is acquired by the construction of experience under certain circumstances. Knowledge is constructed by individuals rather than passively accepted. So learners are the center. All aspects of flipped classroom should be around learners. The model of flipped classroom led by learners was designed as Figure 2.

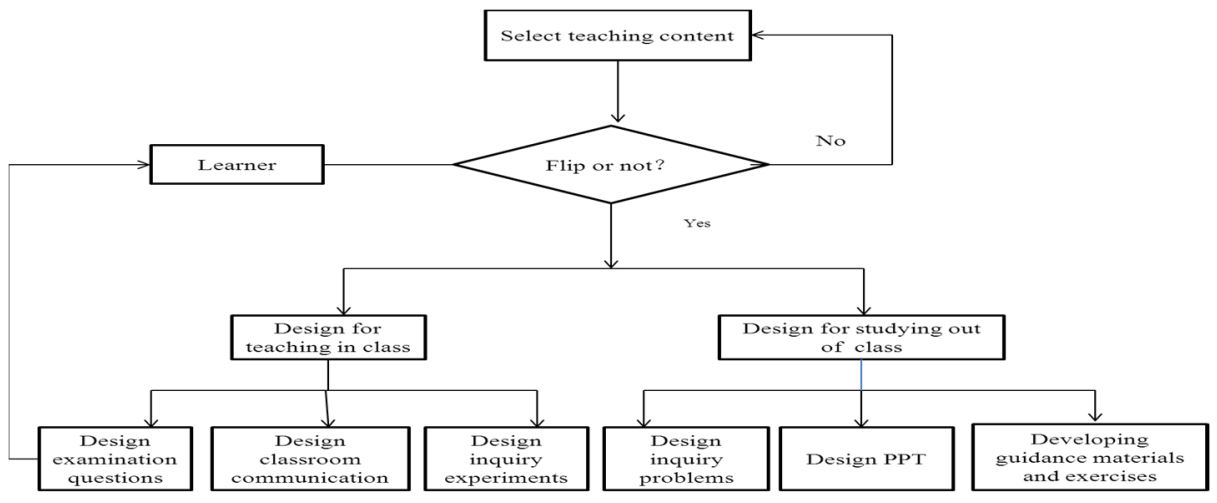

Fig. 2 Model of Flipped Classroom Led by Students

\subsection{Selecting teaching content}

The teaching content of the university can comprise three types: the introduction about the development of the subject, elementary content of basic theory and basic method, and applied content related to practice. Applied content is apt to flip the classroom thanks to its practicality.

In the process of teaching, teachers should decide whether or not adopt flipped classroom teaching according to the content of teaching and the characteristics of learners. Research shows that the flipped classroom is not a suitable teaching form for all teaching contents ${ }^{[9]}$, so some scholars advocate mixed teaching form. No matter which teaching form is adopted, the ultimate goal of teaching is to acquire knowledge. The learner is both the teaching receptor and the subject of the teaching. It is more favorable to the realization of learning objectives by actively choosing suitable teaching forms. Therefore, before flipped classroom design, teachers and students can identify teaching forms together with teaching contents, which are helpful to mobilize the enthusiasm of the students to study. When $80 \%$ of the students choose flipped classroom, the $80 \%$ students can drive the remaining $20 \%$ students to learn out of class and communicate in class during the next group learning process, so the teaching of the flipped class room can be carried out smoothly.

\subsection{Guiding learners' learning needs}

Learning is required to affect learning behavior. In the design of the flipped classroom, in addition to establish the PPT, tutoring materials and exercises of the course for self-study, we should carry out the problem design around the teaching content according to the characteristics of the learners. The learning needs of the learners are driven through the problems. Designed problems are necessary to from easy to difficult. Learners are drawn by problems and eager to resolve the problems, thus producing learning need. Learners finish learning in the process of solving problems out of class, and 
discuss the process of solving problems in class. Each learner learns from others' strong points and bridges the gap, completes the internalization of knowledge, and meets the learning needs.

\subsection{Building the learning values of learners}

Value driven demand. Learners' judgment of learning content determines learners' learning needs. The value of learning can be structured in explicit and implicit values. The explicit value of learning means that learners can achieve collective professional requirements through learning. The implicit value of learning means that learners can master thinking and solving problems through learning. The implicit value of learning has far-reaching influence on learners, but it is often ignored by learners. Therefore, in the design of flipped classroom, PPT, designed problems and exercises need attention to embody the implicit value of learning, such as the choice of research methods, the way to solve the problem, etc.

\subsection{Motivate learners' enthusiasm for learning}

Flipped classroom is actually a classroom for learners. What teachers need to do is to stimulate learners' enthusiasm for learning instead of controlling them. Applied teaching content and problem oriented flip classroom design help to stimulate learners' learning enthusiasm. Teachers explore the exploratory problems under the guidance of the class, and guide learners to complete class learning through PPT, tutorial materials, etc. Group discussion around questions can stimulate learners' thinking zeal. In the course of communication and exploration, teachers' timely comments and guidance inspire the enthusiasm of learners to discuss and explore.

\subsection{Check the learning situation in time}

After completing the learning out of the classroom, the students are obliged to test the learning situation so that the teachers can master the learning situation in time and make corresponding adjustments. Through testing, students can understand their personal learning deficiencies, improve and modify their personal learning methods.

\section{Results and analysis}

The flipped classroom led by students was deployed in the teaching of Environmental Chemistry. The students came from the University for Nationalities, and photochemical smog in Environmental Chemistry was selected as the adaptable content for the flipped classroom led by students. $80 \%$ of the students in the teaching class understand and agree with flipped classroom. Then the flipped classroom was designed as figure 2. Six inquiry questions closely related to teaching contents were designed. The difficulty of the 6 problems was unique and guided students to study before class. PPT and tutorials were provided, and the students were strongly encouraged to selectively further research in the study. The teaching content was segregated into 10 knowledge points and 10 questions for 20 minutes were designed. The questions were used to assess the learning situation before class. The test result was presented in figure 3. From this figure, we can see that $78 \%$ of students can get $60 \%$ knowledge points through the study before class. Then in view of the problems in testing, the questions arranged before class were discussed. By discussion the students can learn from others' strong points and bridge the gap, and solve problems arising from the learning before class. The students were the leaders before class and in class. The teaching result shows that there kind of teaching model was apposite to the class in which the learning bases of the students are different. 


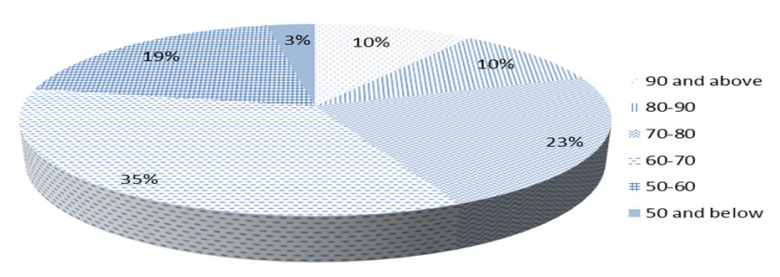

Fig. 3 the Testing Results in Class

The testing results of the knowledge points of Environmental Chemistry were analyzed after final test. It was found that the students can master the knowledge of photochemical smog better than other knowledge points. The flipped classroom makes the students interested in the professional exploration of ecological science. $1 / 5$ of the students in this class participated in university students' innovation projects, and the knowledge was utilized well in their projects.

\section{Conclusions}

Learners are dominant in flipped classroom. Teacher, content of course and adaptability of the learners should be taken into account. It is necessary to select suitable teaching content and according to the characteristics of learners, to design the teaching in class and out of class to guide the learners' study demand, construct reasonable learning values, and mobilize learning enthusiasm of learners.

\section{Acknowledgment}

This research was substantially supported by grants from the education and teaching research and reform project of South West Minzu University (the No. 2017YB16).

\section{References}

[1] Herreid C F, Schiller N A. Case Study: Case Studies and the Flipped Classroom.[J]. Journal of College Science Teaching, 2013, 42(5):62-67.

[2] O"Flaherty J, Phillips C. The use of flipped classrooms in higher education: A scoping review[J]. The Internet and Higher Education, 2015, 25:85-95.

[3] Blair E, Maharaj C, Primus S. Performance and perception in the flipped classroom[J]. Education and Information Technologies, 2016, 21(6):1465-1482.

[4] Delozier S J, Rhodes M G. Flipped Classrooms: a Review of Key Ideas and Recommendations for Practice[J]. Educational Psychology Review, 2017, 29(1) :141-151.

[5] Lai C L, Hwang G J. A self-regulated flipped classroom approach to improving students' learning performance in a mathematics course[J]. Computers \& Education, 2016, 100:126-140.

[6] Koo C L, Demps E L, Farris C, et al. Impact of Flipped Classroom Design on Student Performance and Perceptions in a Pharmacotherapy Course[J]. American Journal of Pharmaceutical Education, 2016, 80(2):33.

[7] Missildine K, Fountain R, Summers L, etc. Flipping the classroom to improve student performance and satisfaction [J]. Journal of Nursing Education, 2013, 52(10): 597-599.

[8] Wen Peng Nian, Jia Guo Ying. Constructionism Theory \& Teaching Reform - a Summary of Constructionism Learning Theory [J]. Theory and Practice of Education, 2002, 22(5): 17-22.

[9] Burak K, Raman M, Paget M, etc. A Mixed Methods Study on the Effect of Flipping the Undergraduate Medical Classroom [J]. Education Sciences, 2017, 7: 83. 